\title{
4.5kV FRD Development for high current power modules
}

\author{
Jiang Liu ${ }^{1, a}$, Yueyang Liu ${ }^{1}$, Rui Jin ${ }^{1}$, Feng He ${ }^{1}$, Shaohua Dong ${ }^{1}$, Yan Pan ${ }^{1}$, Junmin $\mathrm{Wu}^{1}$ \\ ${ }^{1}$ State Key Lab of Advanced Power Transmission Technology, Global Energy Interconnection Research Institute, Beijing, 102209, \\ China
}

\begin{abstract}
A $4.5 \mathrm{kV} / 100 \mathrm{~A}$ FRD was designed by simulation, which had optimized carrier density distribute cell and ruggedness terminal. The cell was composed of P-body $/ \mathrm{N}$-sub/N+ layers, when the P-body doping concentration is lower, the carrier density distribution on the P-body $/ \mathrm{N}$-sub is lower; when carrier density di stribution on the P-body/N-sub side is lower than that on the $\mathrm{N}$-sub/N+ side, the FRD has soft recovery but bad surge-current capability. So the P-body doping concentration needs trade-off consideration. Lifetime co ntrol technology was also used to optimize the carrier density distribution and trade-off characteristics. The $t$ erminal has high breakdown voltage, low electric field and large process window, which means more rugge dness and high reliability. The experiment results show that the design chip and competitor chip has nearly $t$ he same trade-off characteristics, the design chip has larger dynamic loss but lower static loss. The design $\mathrm{c}$ hip has high surge current, the surge current is 13 times as much as the rate current.
\end{abstract}

\section{Introduction}

Fast Recovery Diodes (FRD) is usually used as freewheeling diode in anti-parallel to the IGBTs, which is an effective solution for easier controlled in the field of power systems. The low losses and soft switching behaviour of the diode attract the most attention. It requires current ratings of $50 \mathrm{~A}$ to $300 \mathrm{~A}$ per chip and blocking voltages in the range of $1.7 \mathrm{kV}$ to $6.5 \mathrm{kV}$ in power system applications. The working frequency of the chips in power system applications is in the range of $100 \mathrm{~Hz}$ to $15 \mathrm{kHz}$. The chips can be used for Flexible Alternating Current Transmission Systems (FACTS), DC circuit breaker and High-Voltage Direct Current (HVDC), etc. The device with lower conduction voltage can effectively reduce the loss of the conduction, thus the total loss is diminished. The applications also require reverse recovery softness, high ruggedness and good surge-current capability.

During the past two decades, a lot of studies have been done in the field of FRDs. It has been demonstrated that several concepts (such as CIBH, FCE) offer a significantly improved characteristics ${ }^{[1-3]}$. However, it is difficult to optimize the trade-off characteristics. In this paper, optimized structure and lifetime were proposed, the anode emission efficiency was optimized and carrier lifetime was killed by lifetime control technology. The experiment show low conduction loss, soft reverse recovery and good surge-current capability.

\section{Structure design}

The $4.5 \mathrm{kV} / 100 \mathrm{~A}$ diode cell structure is shown in Fig.1. It is composed of P-body $/ \mathrm{N}$-sub/N+ layers, the P-body contact with the anode electrode, and the $\mathrm{N}+$ contact with the cathode electrode.

The three layer thickness and doping profile need careful consideration to get low loss, high ruggedness and good surge-current capability. The optimized P-body peak concentration is $2 \mathrm{E} 17 / \mathrm{cm} 3$ and depth is about $10 \mu \mathrm{m}$. The $\mathrm{N}$-sub doping concentration is about $1 \mathrm{E} 13 / \mathrm{cm}^{3}, 430 \mathrm{ohm} . \mathrm{cm}$, and thickness is $500 \mu \mathrm{m}$. The N+ peak concentration is near $1 \mathrm{E} 20 / \mathrm{cm}^{3}$ and depth is about $40 \mu \mathrm{m}$. It's important to point out that the surface of Pbody has higher doping nearly $1 \mathrm{E} 19 / \mathrm{cm}^{3}$ to ensure ohm contact.

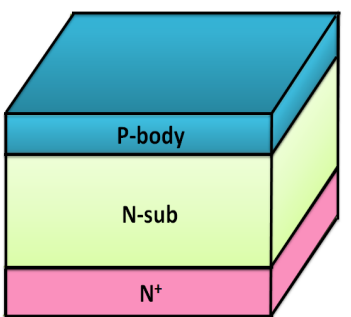

Figure 1. Schematic cross sections of cell

The $4.5 \mathrm{kV} / 100 \mathrm{~A}$ diode terminal structure is shown in Fig.2. It is composed of multi-deep P-rings (PRs) and total dimension is about $1.8 \mathrm{~mm}$. The PR width, PR space and passivation process needs optimization.

a Corresponding author: xiaojiang2012@126.com 


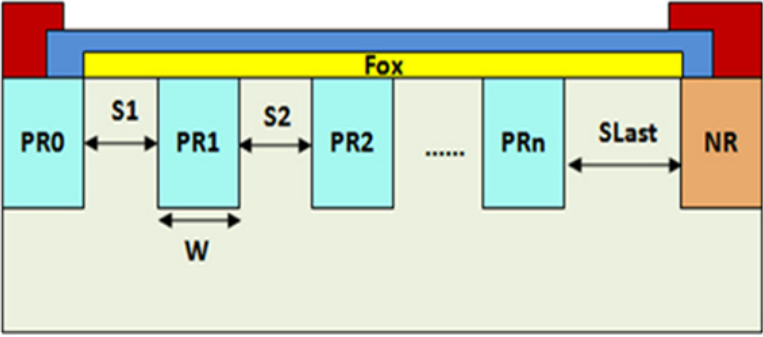

Figure 2. Schematic cross sections of terminal

\subsection{Cell design}

The cell characteristic was determined by carrier density distribution. When carrier density distribution on the Pbody/N-sub side is lower than carrier density distribution on the $\mathrm{N}-\mathrm{sub} / \mathrm{N}+$ side, the FRD has soft recovery ${ }^{[4-6]}$. The removal of the plasma will start more rapidly at the P-body/N-sub junction than at the $\mathrm{N}-\mathrm{sub} / \mathrm{N}+$ junction, and result in the final plasma remains within the $\mathrm{N}$-sub region near $\mathrm{N}-\mathrm{sub} / \mathrm{N}+$ junction and soft recovery ${ }^{[7]}$.

The carrier density distribution on the P-body/N-sub side depends on the P-body doping concentration. When the P-body doping concentration increases, the carrier density increases, the conduction loss is lower but has bad surge-current capability, vice versa. So P-body doping concentration needs carefully consideration. Lifetime control technology was also used to optimize the carrier density distribution and trade-off characteristics.

Fig. 3 shows simulation result of $4.5 \mathrm{kV} / 100 \mathrm{~A}$ diode reverse recovery behaviour, which has a soft recovery. The peak reverse recovery current is about $120 \mathrm{~A}$, a little more than rated current.

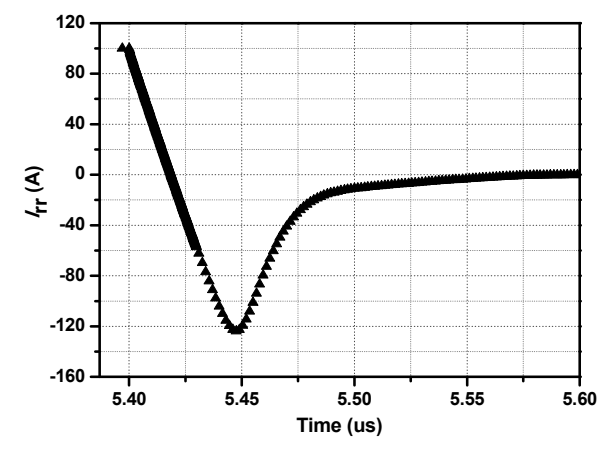

Figure 3. Simulated current profiles under reverse recovery conditions (Conditions: $V_{\mathrm{R}}=2.8 \mathrm{kV}, I_{\mathrm{F}}=100 \mathrm{~A}, d i / d t=600 \mathrm{~A} / \mathrm{us}$, $T_{\mathrm{j}}=25^{\circ} \mathrm{C}$ )

Fig. 4 shows the holes density distribution during the reverse recovery time. The cathode side has remained holes at tail time, lead to soft reverse recovery behaviour. It's important to point out that Fig. $4 \mathrm{t}=0 \mu \mathrm{s}$ is corresponding to Fig. $3 \mathrm{t}=5.4 \mu \mathrm{s}$.

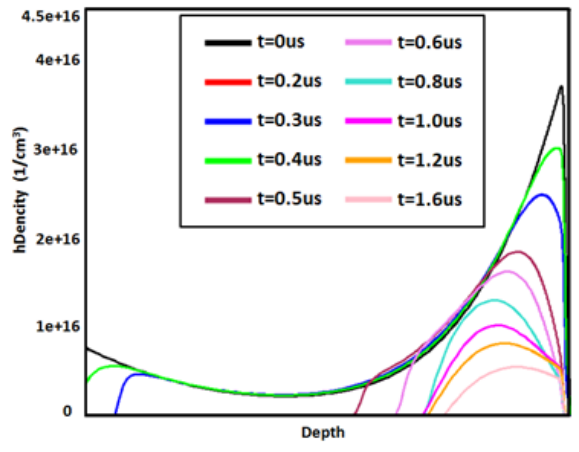

Figure 4. The simulated holes density distribution during the reverse recovery time

\subsection{Terminal design}

Fig. 5 shows the breakdown voltage of the terminal, the breakdown voltage exceeds $6000 \mathrm{~V}$ and is more than 1.3 times as much as rated voltage. The high voltage margin results in high reliability.

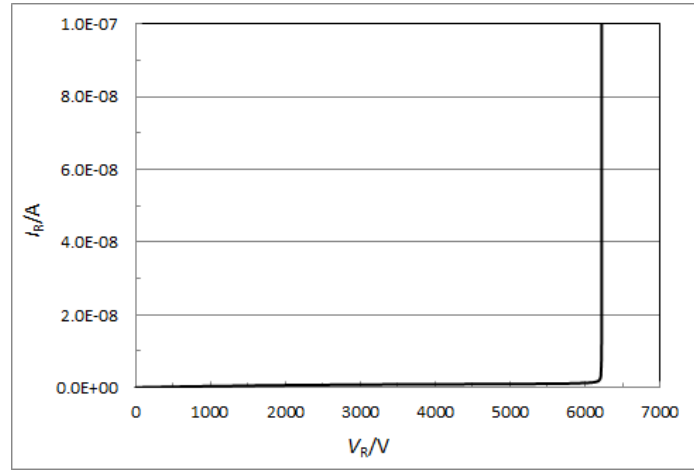

Figure 5. The breakdown voltage of terminal

Fig. 6 shows the electric field distribution of terminal at breakdown voltage, the peak electric field was on the middle of the terminal and was lower than $2.1 \mathrm{E} 5 \mathrm{~V} / \mathrm{cm}$. The low peak electric field and parabolic electric field profile lead to more ruggedness and high reliability.

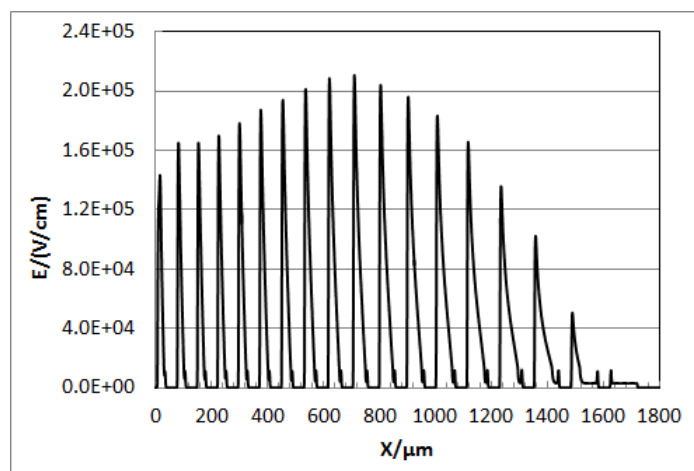

Figure 6. The simulated electric field of terminal

Table.1-3 show window check simulation result of terminal. Along with PR dosage and N substrate doping concentration decrease, the breakdown voltage increase. The PR width vary $4 \mu \mathrm{m}$ has no obvious effect on breakdown voltage. 
Table 1. The breakdown voltage against different dose of P-

\begin{tabular}{|c|c|}
\multicolumn{2}{|c|}{ ring } \\
\hline PR dose $\left(\mathbf{c m}^{-2}\right)$ & Breakdown voltage $(\mathbf{V})$ \\
\hline $\mathbf{3 . 0 0 E}+\mathbf{1 3}$ & 5800 \\
\hline $\mathbf{6 . 0 0 E}+\mathbf{1 3}$ & 5960 \\
\hline $\mathbf{1 . 0 0 E}+\mathbf{1 4}$ & 6275 \\
\hline
\end{tabular}

Table 2. The breakdown voltage against different N-sub doping concentration

\begin{tabular}{|c|c|}
\hline N-sub concentration $\left(\mathbf{c m}^{-3}\right)$ & Breakdown voltage $(\mathbf{V})$ \\
\hline Sub+20\% & 5810 \\
\hline Sub & 6275 \\
\hline Sub-20\% & 6730 \\
\hline
\end{tabular}

Table 3. The breakdown voltage against different width of Pring

\begin{tabular}{|c|c|}
\hline PR width $(\boldsymbol{\mu m})$ & Breakdown voltage $(\mathbf{V})$ \\
\hline $\mathbf{W}-4$ & 6258 \\
\hline W & 6275 \\
\hline $\mathbf{W}+\mathbf{4}$ & 6267 \\
\hline
\end{tabular}

\section{Experiment Results}

The $4.5 \mathrm{kV} / 100 \mathrm{~A}$ FRD chip was fabricated base on the simulation. After fine-tune the process, especial lifetime control condition, the static and dynamic characteristics meet the design target.

Fig.7 shows the optics microscope picture of $4.5 \mathrm{kV}$ /100A FRD wafer.

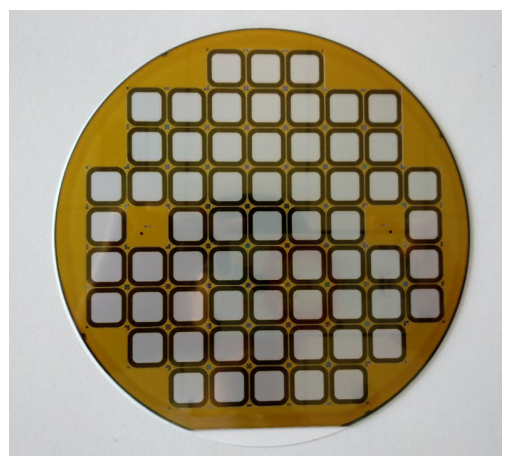

Figure 7. Optics microscope picture of $4.5 \mathrm{kV} / 100 \mathrm{~A}$ FRD wafer

Fig. 8 shows the breakdown voltage mapping test result, the voltage was about $6150 \mathrm{~V}$, meet the simulation result.

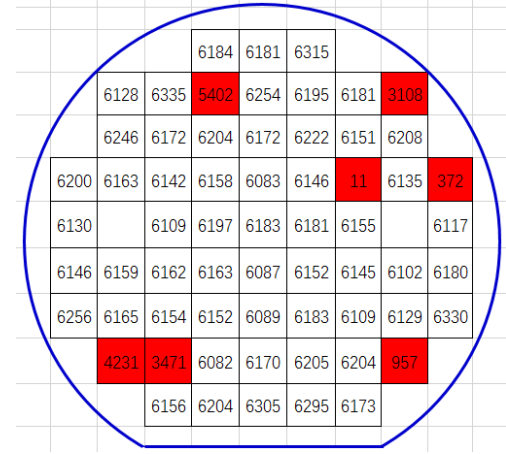

Figure 8. Experiment breakdown voltage mapping data. (Conditions: $I_{\mathrm{r}}=1 \mathrm{~mA}, T_{\mathrm{j}}=25^{\circ} \mathrm{C}$ )

Table 4 shows the static characteristics between the design chip and a competitor chip. The design chip forward voltage was lower than competitor and the reverse leakage current was on the same lever.

Table 4. Static characteristics comparison between own design and competitor chip

\begin{tabular}{|c|c|c|c|c|}
\hline Characteristics & \multicolumn{2}{|c|}{$V_{\mathbf{f}} / \mathbf{V}$} & $I_{\mathbf{r}} / \mu \mathbf{A}$ & $I_{\mathbf{r}} / \mathbf{m A}$ \\
\hline Bias & \multicolumn{2}{|c|}{$100 \mathrm{~A}$} & \multicolumn{2}{c|}{$4500 \mathrm{~V}$} \\
\hline Temperature/ ${ }^{\circ} \mathrm{C}$ & 25 & 125 & 25 & 125 \\
\hline Design chip & 2.46 & 2.68 & 0 & 0.75 \\
\hline Competitor chip & 2.82 & 3.06 & 0 & 1.10 \\
\hline
\end{tabular}

Table 5 shows the dynamic characteristics between the design chip and a competitor chip. The design chip dynamic characteristic was larger than competitor.

The design chip and competitor chip has nearly the same trade-off characteristic, the design chip has larger dynamic characteristic but lower static characteristic.

Table 5. Dynamic characteristics comparison between own design and competitor chip

\begin{tabular}{|c|c|c|c|c|c|c|c|c|}
\hline Characteristics & \multicolumn{2}{|c|}{$\boldsymbol{I}_{\mathrm{RM}} / \mathrm{A}$} & \multicolumn{2}{|c|}{$Q_{\mathrm{rr}} / \mu \mathrm{C}$} & \multicolumn{2}{|c|}{$T_{\mathrm{rr}} / \mu \mathrm{s}$} & \multicolumn{2}{|c|}{$E_{\text {ree }} / \mathbf{m J}$} \\
\hline Bias & \multicolumn{8}{|c|}{$V_{\mathrm{R}}=2800 \mathrm{~V}, V_{\mathrm{GE}}=+/-15 \mathrm{~V}$} \\
\hline Temperature $/{ }^{\circ} \mathrm{C}$ & 25 & 125 & 25 & 125 & 25 & 125 & 25 & 125 \\
\hline Design chip & 150 & 154 & 50 & 62 & 0.60 & 0.75 & 22 & 27 \\
\hline Competitor chip & 109 & 129 & 32 & 48 & 0.50 & 0.67 & 14 & 22 \\
\hline
\end{tabular}

Fig.9 and Fig.10 shows design chip has soft reverse recovery behaviour at room and high temperature. 


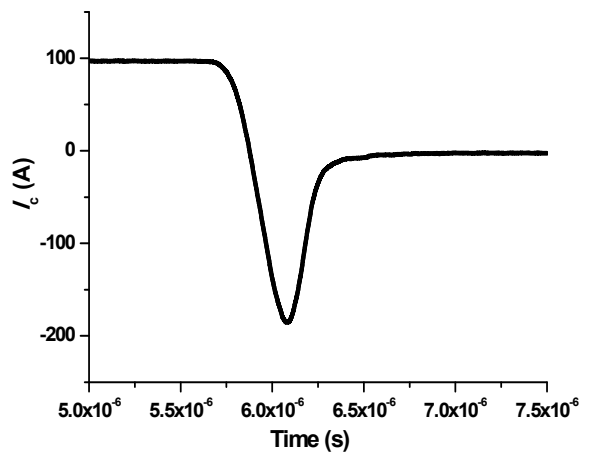

Figure 9. Experiment current profiles under reverse recovery conditions. (Conditions: $V_{\mathrm{R}}=2.8 \mathrm{kV}, I_{\mathrm{F}}=100 \mathrm{~A}, d i / d t=600 \mathrm{~A} / \mathrm{us}$, $T_{\mathrm{j}}=25^{\circ} \mathrm{C}$ )

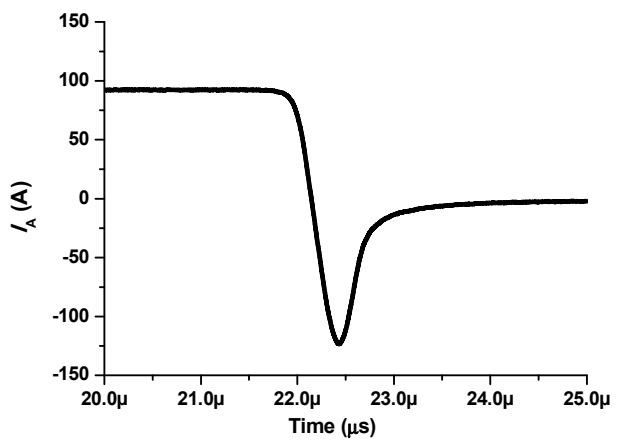

Figure 10. Experiment current profiles under reverse recovery conditions. (Conditions: $V_{\mathrm{R}}=2.8 \mathrm{kV}, I_{\mathrm{F}}=100 \mathrm{~A}$, $d i / d t=600 \mathrm{~A} / \mathrm{us}$, $T_{\mathrm{j}}=125^{\circ} \mathrm{C}$ )

The design chip also has high surge current, the surge current is 13 times as much as the rate current.

\section{Conclusions}

In conclusion, a $4.5 \mathrm{kV} / 100 \mathrm{~A}$ FRD was designed with the aid of simulation tools and verified by experiment.

The FRD trade-off characteristics were determined by the carrier density distribution. Low concentration Pbody doping lead to soft recovery but had surge-current capability, so P-body doping concentration need tradeoff consideration. Lifetime control technology is also a useful tool to optimize the carrier density distribution. The terminal simulation results show high breakdown voltage, low electric field and large process window, which mean more ruggedness and high reliability.

This device was fabricated and the test results show that the design chip and competitor chip has nearly the same trade-off characteristics, the design chip has larger dynamic loss but lower static loss. The design chip also has high surge current, the surge current is 13 times as much as the rate current.

\section{Acknowledgment}

Project supported by National Key R\&D Program of China (No. 2016YFB0901800).

\section{References}

1. Kopta, M. Rahimo, The Field Charge Extraction (FCE) Diode- A Novel Technology for Soft Recovery High Voltage Diodes, Proceedings of the 17 International Symposium on Power Semiconductor Devices \& IC's May 23-26, 2005 Santa Barbara, CA, pp83-86.

2. Min Chen, Josef Lutz, Martin Domeij, Hans Peter Felsl, Hans-Joachim Schulze, A Novel Diode Structure with Controlled Injection of Backside Holes (CIBH), Proceedings of the 18th International Symposium on Power Semiconductor Devices \& IC's June 4-8, 2006 Naples, Italy.

3. Tomonori Mizushima, Michio Nemoto, Hidenao Kuribayashi,Takashi Yoshimura and Haruo Nakazawa, Inhibiting Effect of Middle Broad Buffer Layer Diode Using Hydrogen-Related Shallow Donor on Reverse Recovery Oscillation, Proceedings of The 22nd International Symposium on Power Semiconductor Devices \& ICs, Hiroshima 2010 pp.115-118.

4. J. Lutz, U. Scheuermann: "Advantages of the New Controlled Axial Lifetime Diode", PCIM proceedings (1994).

5. T. Laska, L. Lorenz, A. Mauder, The Field Stop ICBT Concept with an Optimized Diode“, Proceedings of the 41th PCIM, Numberg 2000.

6. Josef Lutz, Fast Recovery Diodes - Reverse Recovery Behaviour and Dynamic Avalanche, PROC. 24th INTERNATIONAL CONFERENCE ON MICROELECTRONICS (MIEL 2004). VOL 1, NIS, SERBIA AND MONTENEGRO, 16-1 9 MAY, 2004.

7. CHEN Zuliang, YUE Wei, LI Zhaolong, et al. Improvement of reverse breakdown characteristics of bipolar switching transistors by electron irradiation[J]. Semiconductor Technology, 2014, 39(12): 943-946. 